\title{
TOWARDS NEW EXPERIENCES FOR INTERNATIONAL COOPERATION: A MULTIDISCIPLINARY ICT AND BUSINESS INTERNATIONAL PROJECT
}

\author{
I. Seruca ${ }^{1}$, K. Suilen ${ }^{2}$, L. Wijgergangs ${ }^{2}$ \\ ${ }^{1}$ Universidade Portucalense, REMIT \& Univ. do Minho, Centro Algoritmi (PORTUGAL) \\ ${ }^{2}$ Fontys University of Applied Sciences - School of ICT (NETHERLANDS)
}

\begin{abstract}
A new experience in International Cooperation was launched by Fontys Hogeschool ICT, Netherlands in the form of an Interdisciplinary ICT and Business International Project, involving Bachelor third-year students and teachers from several Higher Education Institutions (HEI) partners. The main project objectives are International cooperation and awareness, demonstrating entrepreneurship behavior and an interdisciplinary vision. This kind of International Cooperation overcomes the problems often found in other mobility actions' applications under the Erasmus+ Programme framework, where high quality standards, rigid schemes of functioning and other selection criteria may hamper the possibilities for recognition and funding.

This paper describes the development and implementation of an Interdisciplinary ICT and Business International project, supervised by the authors, aiming to develop innovative Business IT solutions under the central topic "Obesity \& healthy lifestyle". The project was developed both in loco and in a remote way, where the initial kick-off was made at Fontys ICT and the closure at the second HEI partner, Portucalense University and involved students from both HEls with ICT and business backgrounds. The work of the four project student teams is described, the methodology and outcomes assessed and lessons learnt are highlighted. The results of the assessment, conducted to measure both learning outcomes and student satisfaction with and opinions of the project, are included along with a summary of the experience gained by students and teachers while taking part in the project. The paper aims to share implementation and assessment of such a project as an opportunity for HEl's to acknowledge new ways of international cooperation, for entrepreneurship educators to learn from others' experiences, and to contribute to the entrepreneurship education literature.
\end{abstract}

Keywords: International cooperation, International project, entrepreneurship, interdisciplinary, ICT and Business.

\section{INTRODUCTION}

In the process of envisaging International Cooperation involving a group of students as well as coaching teachers from Higher Education Institutions (HEI) in the same mobility action there are a number of wellknown possibilities mainly within the Erasmus+ KA2 framework. These mobility options have, however, to obey in duration, outline, contents and functioning to the high quality standards as well as strict criteria set by the European Commission's Erasmus+ to be accepted for recognition and funding. It may not be easy for a $\mathrm{HEI}$ to involve a reasonable number of students studying and working together within these actions, due to constraints of students to be abroad for longer periods of time, financial constraints or unsuccessful applications.

A new experience in International Cooperation was launched by Fontys Hogeschool ICT, Netherlands in the form of an Interdisciplinary ICT and Business International Project, involving Bachelor 3rd year students and teachers from several HEl partners. The project, held annually and currently in its 3rd edition, involves five to six HEl partners, each of them participating with an exchange of a group of 10 students that are combined with 60 students from Fontys Hogeschool ICT. Work teams are set with 5 to 7 students, where two or three students are from each partner. Participating students may have an ICT and/or Business/Management background to allow for interdisciplinary project teams.

The students that participate in this project, have various reasons for doing so: Fontys has the largest group of participating students since its overall population is also the biggest and the international project is a mandatory part of their curriculum; other HEl's include it as an extracurricular activity. This is the underlying reason of a group always consists of Dutch (Fontys) students and one other HEl. 
The main project objectives are International cooperation and awareness, demonstrating entrepreneurship behavior and an interdisciplinary vision. Generically, the project will aim to apply new trends or developments in the area of IT in a business and develop entrepreneurial skills and cooperative work in multidisciplinary and international student teams. The Project-based learning (PBL) approach is used overall for project development [1], [2] along with the Peer Assisted Learning method [3].The students all have different educational backgrounds and can use this project to deepen their understanding of a subject by showing/explaining their deliverables to their peers.

Central kick-off with students from all cooperating partners is held in Fontys University of Applied Sciences, Eindhoven. During the first two days, student teams in cooperation with lecturers from partner institutions define the project plan to be developed (objectives and scope, responsibilities, deliverables, scheduling, methodology, resources and tools, etc.); the 3rd day is reserved for cultural activities. Each team then works remotely (online) for the development of the project; for remote work, it is estimated at least half a day of work per week for 5 to 6 weeks, totaling 3 full work days per student. The closing of the project will involve 2 working days, including the final presentation and will be done at the location of the 2nd partner HEl; a 3rd day for cultural activities is also considered.

This paper describes the Interdisciplinary ICT and Business International project, undertaken between February and April 2019 and supervised by the authors, involving both Fontys ICT and Portucalense University (UPT) as HEls partners and 23 students, aiming to develop innovate Business IT solutions under the central topic "Obesity \& healthy lifestyle". The work of the four project student teams will be described, the methodology and outcomes assessed and lessons learnt will be highlighted.

The paper is structured as follows: Section 2 describes the underpinning active-teaching methodology used overall for project development and identifies some related work use of this methodology for entrepreneurship teaching. In Section 3 we provide an overview of the overall project's programme and way-of-working and a summary of the students' teams' developed projects and deliverables. In Section 4 the assessment of the work undertaken by students is generally depicted, conducted to measure both learning outcomes and student satisfaction with and opinions of the project. Finally, Section 5 concludes with a summary of the experiences gained both by students and teachers while taking part in the project and some insights or suggestions for future editions of the project.

\section{THE PROJECT-BASED LEARNING APROACH AS A METHOD FOR TEACHING ENTREPRENEURSHIP}

\subsection{Project-based learning (PBL)}

Project-based learning (PBL) is a well-known method to the educational society; it is a pedagogical approach that involves active learning, investigating and solving complex, real-world problems [1], [2]. The problem is used as a starting point around which the teaching and learning of knowledge and skills development is planned and constructed. During the experience, students function as self-directed learners and work in teams to collaborate on solutions to open-ended challenges [2]. Students usually present their findings, including the process and solution(s) to the problem, as well as a product (a physical item or plan as part of the solution) to a selected audience consisting of peers or members of a target group.

Under the PBL setting, the students fulfil an active and participatory role in their own learning process, while the lecturer facilitates and guides this learning process, rather than being the primary source of knowledge. Lecturers (or teachers) fulfil the roles of facilitator and mentor in PBL to support the development of students' thinking skills and provide scaffolding for students' metacognitive processes. Facilitators also act as motivators to foster the learning process in PBL. Students play a prominent role in their own learning in PBL, becoming creators of knowledge, as part of a self-directed learning process, which is guided by the facilitator (lecturer). The PBL phase model and actors involved are generally depicted in Figure 1.

There is a consensus that using PBL as a main teaching/learning strategy holds several advantages for students, including that real-life problems (that are often related to global issues) are addressed, students learn to value the opinions of others through collaborative work, and important 21st century skills are developed, such as communication skills, planning skills, higher-order thinking, critical thinking and lifelong learning [1]. 


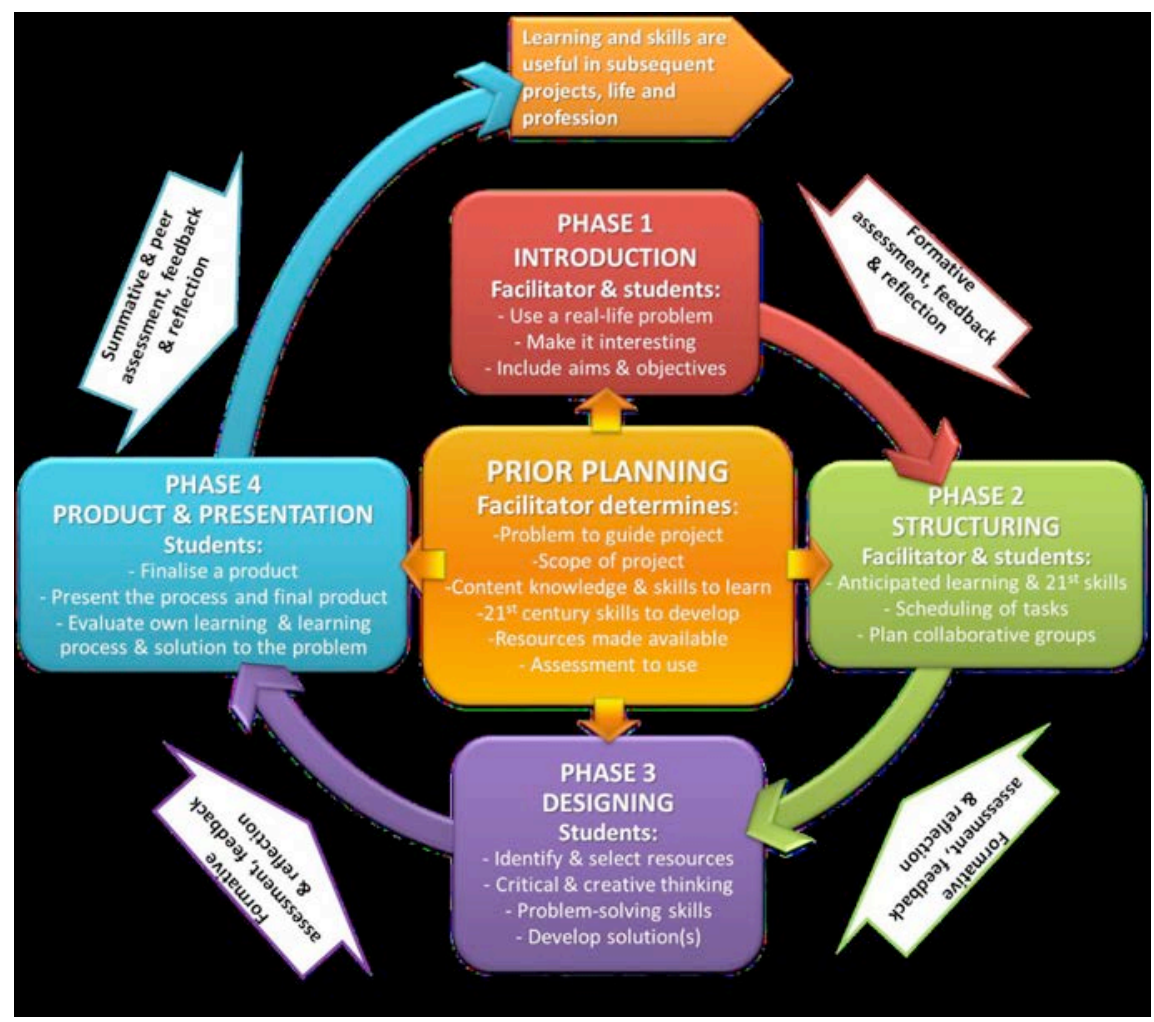

Figure 1. PBL common phases and actors (source: [1])

\subsection{PBL as an enabler for an entrepreneurship mindset}

As a key competence recognized both in technology and business oriented undergraduate curriculum studies, entrepreneurship does not necessarily involve a specific school subject. Rather, it requires a way of teaching in which experimental learning and project work have a main role. Teachers do not provide students with the answers, rather help them to research and identify the right questions and find the best answers [4]. The PBL approach allows this way of acquiring entrepreneurship skills. Furthermore, the potential outcomes of PBL are aligned with the three C's of the entrepreneurial mindset (Creativity, Curiosity, and Connections) [5] and there are several reported uses of PBL for Entrepreneurship teaching [2],[6],[7],[8],[9].

As an example of the PBL promotion of the three C's application, students who must operate as selfdirected learners have to be curious. Second, students who work on problems that have an authentic context are learning to keep a stakeholder's needs in mind when developing an innovative solution; this is a guiding element of creation of value. Finally, students who know how to effectively leverage the expertise and insights of the team while working toward a common, and open-ended goal in PBL understand the value of making connections. We therefore argue that the inherent characteristics of PBL naturally promote the development of an entrepreneurship mindset (as outlined by the three C's) regardless of the specific project objectives.

Thus, we draw on these conceptual ties and reported uses of PBL for Entrepreneurship teaching and use this active learning approach for the development of our International Project.

\section{OVERVIEW OF THE PROJECT'S PROGRAMME AND STUDENTS TEAMS WORK}

\subsection{Project way-of-working and schedule}

The project started on February 25, 2019 at Fontys University of Applied Sciences, Eindhoven. For two days, the students from several HEIs (Fontys ICT NL; VŠE-University of Economics, Prague CZ; IBA Kolding, Denmark DK; Portucalense University PT; Universal Business School, Mumbai, India) met each other in the same location (or virtual in the case of Mumbai) and teams were made consisting of students with different backgrounds from pairs of HEls partners, including Fontys ICT. 
The objectives and central topic ("Obesity \& healthy lifestyle") were presented and the programme started with an inspiration session given by the CEO of BusVit (www.busvit.com), a company working on the business of food health and lifestyle. Students were challenged to come up with ideas that address a self-chosen issue in this topic. From that point, student teams started to brainstorm and work on their own projects business ideas, with specific to cultural differences for their chosen issue to spot potential opportunities. They were asked to define the project plan (objectives and scope, responsibilities, deliverables, schedule, methodology, resources and tools, etc.) and at the end of the second work day, they made group presentations of their projects with subsequent feedback given by the whole group of teachers of participating HEls.

The closure schedule was agreed with the teachers from both HEls involved in the groups. For the groups including Fontys ICT and UPT students, the project closing days were set to April 8-9, 2019 at UPT Porto-based campus.

From end of February to beginning of April (around 6 weeks), the student groups worked in a remote way using a set of groupware tools for communication and file sharing. These tools varied from WhatsApp, Slack, Microsoft Teams to regular email and Skype.

The closing project schedule at UPT included in the first day the groups' status update (pitches) on their work progress with subsequent feedback and suggestions for improvement towards the end given by the coaching teachers as well as other teachers involved in entrepreneurship teaching from UPT. A workshop on Growth Hacking was provided to the students, so that they could get better insights on the ways to create value from their projects and better define their growth strategy. The second work day mainly targeted in the morning the groups' working sessions and in the afternoon the groups peer evaluation sessions followed by a discussion with the coaching teachers to share experiences obtained with the project. The groups' final presentations were then undertaken with feedback given and assessment made by the same group of teachers of the previous day. The project ended with a posters exhibition of the projects developed.

\subsection{Students' developed projects and deliverables}

As mentioned above, all the students' projects should address the central topic ("Obesity \& healthy lifestyle"). For the groups including Fontys ICT and UPT students, projects developed ranged from a plugin system for online stores for healthy groceries purchase suggestions (Perfect Orientation for Healthy Optimization [Poho] Healthy Solutions System), an app to motivate sports practising by promoting social connections of gym practitioners (Gymbuddy), an app for food and drinks recommendation in case of hangover or mild illness symptoms (Freshop) and an Al based voice assistant for recipes recommendation based on diet requirements, food and time available for cooking (Happy Table).

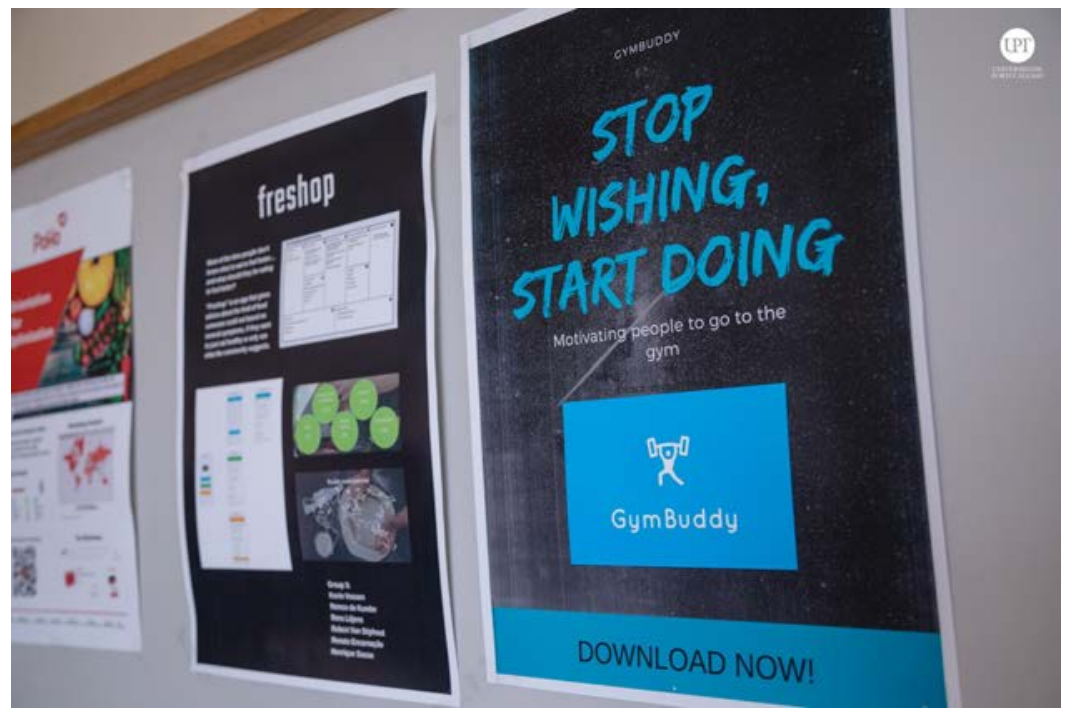

Figure 2. Posters exhibition of the projects developed

As deliverables, all the groups developed an intermediate project summary used by teachers as a basis for the groups status update evaluation session held on the first day of the return visit. End deliverables 
included canvas business models, market research studies/reports and mock-ups or clickable demos of the projects that were used in the final live presentations for better illustrating the behaviour of their future end products. They also developed graphical A3 posters for their projects which were shared at the final posters exhibition session (Fig. 2). All the deliverables were submitted as work activities under a UPT elearning Moodle platform area specifically created for the International project, allowing for future sharing of project experiences and results.

\section{ASSESSMENT}

Assessment of students' work was done at two moments during the project: at the end of the first two days, where students had to pitch their idea and project plan, and at the end of the project which also included peer evaluations and teachers' evaluation of the final presentations and deliverables.

The international project serves two main objectives in the student's learning path:

1 A proof of craftmanship in the respective fields of knowledge (group level)

2 A means to contribute to the professional development skills of the students, with a focus on virtual collaboration, intercultural awareness and project management (individual)

During the previous roll-outs of this international project, we found that each participating HEl had its own assessments objectives and methods, due to the diversity among the participants. Building on this experience, both a generic assessment form was developed which is used to assess the student groups, and a peer evaluation is used for the second learning objective.

The assessment form (Fig. 3) which looks at the first learning objective consists of the following dimensions and criteria:

\begin{tabular}{|c|c|c|c|c|c|c|}
\hline Dimension & Criteria & $\mathrm{I}$ & S & G & VG & Feedback \\
\hline Knowledge and insight & $\begin{array}{l}\text { The student answers questions on knowledge from the top of } \\
\text { their heads with objective knowledge gained during the } \\
\text { International Project. } \\
\text { The student answers questions on insight by making use of } \\
\text { knowledge and insight gained during the International Project } \\
\text { and answers these questions in their own words, and } \\
\text { summarize and explain the related knowledge and insight. }\end{array}$ & & & & & \\
\hline $\begin{array}{l}\text { Applied knowledge and } \\
\text { insight }\end{array}$ & $\begin{array}{l}\text { By means of the deliverables the student demonstrates that } \\
\text { the gained knowledge and insight of the different subjects of } \\
\text { the International Project are applied in an innovative, flexible } \\
\text { and meaningful way. }\end{array}$ & & & & & \\
\hline Judgment & $\begin{array}{l}\text { The student collects and interprets relevant data for their } \\
\text { deliverables, with the goal of forming a judgment that is based } \\
\text { on relevant social, scientific and/or ethical aspects. }\end{array}$ & & & & & \\
\hline Communication & $\begin{array}{l}\text { The student transfers information, ideas and solutions to a } \\
\text { public consisting of (non-)specialists. }\end{array}$ & & & & & \\
\hline
\end{tabular}

Figure 3. Dimensions and criteria for assessment

At the end of the second (return) visit, a panel of experts, from both the hosting institution and the visiting partner, question the students after a pitch presentation and they jointly score the various groups. Students can then use the feedback provided and the results obtained as proof in their own institution's way of assessment. At Fontys, for example, students use the project deliverables (documents, prototypes, code) and the assessment input, as validated evidence for their learning objectives.

The second objective, regarding professional development, can be proven by means of peer evaluations and written reflections. Each student fills in a peer evaluation of the group members and for the group process as a whole (Fig. 4). 


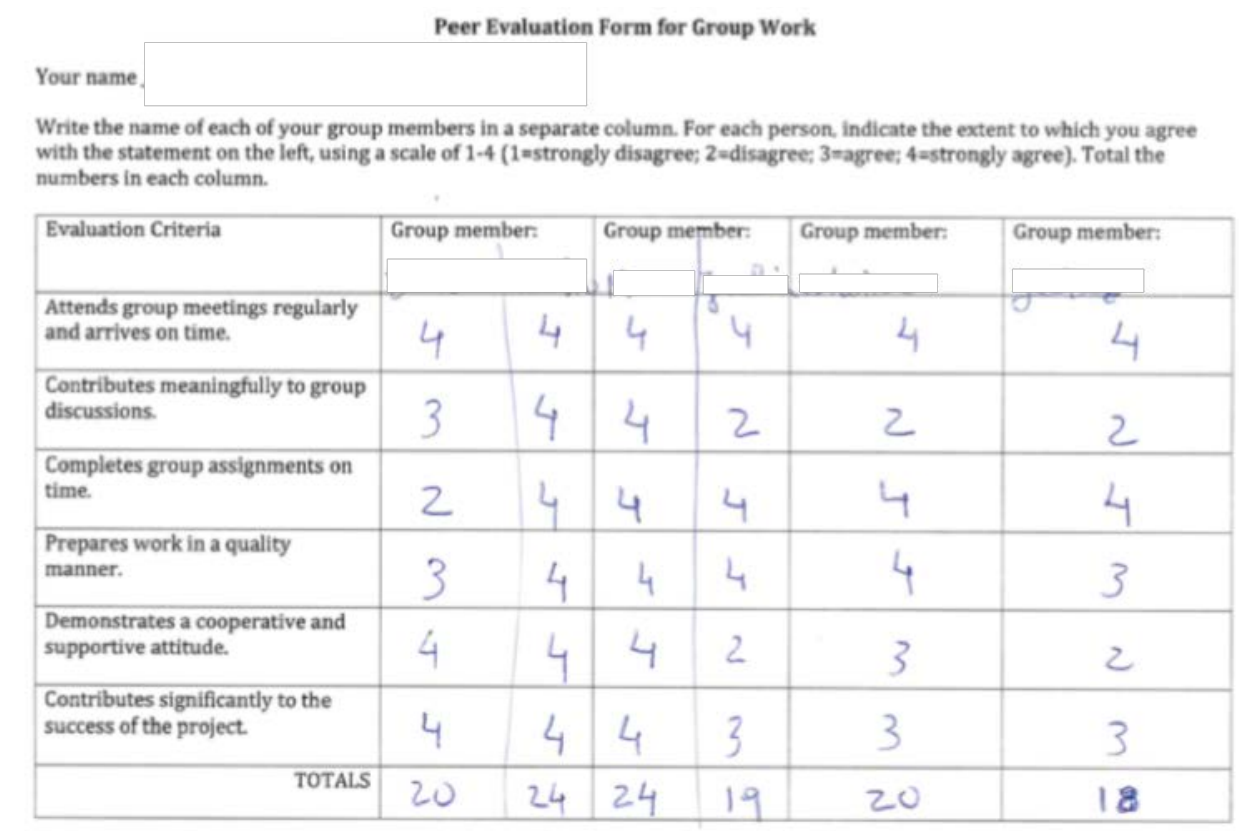

Figure 4. Sample peer evaluation form

The evaluations forms are then used by the assessors to have a group meeting in which more details can be given or ratings can be explained. The outcomes can be used by the students as proof of their professional skills and are used by the participating lecturers to further improve the project the next year

\subsection{Results}

For the results, we take a look at the Portuguese-Dutch groups, since not all results were in at the time of writing. In general, we see that the groups who spent most time on the project when they could work together in the same location, also rate each other the highest (24 out of $30 \mathrm{pts}$ ). Two groups had a more difficult time finding an effective collaboration and rated each other lower (15/19 out of 30 pts). However, in the evaluation meeting, these groups could better describe their lessons learned and demonstrated a higher level of understanding the issues in working on such a project. The group that rated each other best for their collaboration, also was the group that was voted for as best by the panel of experts. Therefore, there seem to be two ways of 'winning':

- Effective collaboration, and a good project result

- Less effective collaboration and results, but higher degree of understanding \& development of their professional skills.

\section{CONCLUSION AND FURTHER WORK}

In this section we want to address some lessons learned and conclusions we can draw after three executions of this project:

1 Focus on teambuilding at the start: The project starts with 2 days on location, where the team members first meet each other. In the evaluations it showed that the more time the members spend together and discuss their backgrounds, the better the working relationship. Some ways the tutors can help the students to achieve this:

- Prepare a Persona or Passport of yourself

- Discuss your typical work/study week or semester

- By means of a game, like "challenge assumptions": everyone writes down cultural assumptions and these are then discussed.

2 Do not underestimate the communication barrier. For most participating students, English is not their mother's tongue. Add the primary choice of communication channel (WhatsApp) to that and realize that a lot is lost in translation. Therefore, we suggest that at least 2 voice/video meetings are facilitated during the virtual phase of the project. By adding intermediate milestones and 
discussing them on a group video conference, this issue can be tackled. Student's also mention that speaking generally goes better than writing.

3 Share previous work of group members, to establish an idea of each other's knowledge level and way of working.

4 Adding cultural activities early on in the project and also at the start of the return visit, makes for a better team spirit.

5 The timespan for the most recent project was about 8 weeks, with 6 weeks of virtual collaboration. This puts enough pressure on the project but also leaves enough room to experience the difficulties of virtual collaboration.

\section{REFERENCES}

[1] A. Du Toit, "A framework for project-based learning in Consumer Studies teacher preparation". International Journal of Home Economics, 10(2), 171-179, 2017.

[2] C. Vignola, J. London, R. Ayala, W. Huang, "Cultivating an Entrepreneurial Mindset in an Undergraduate Engineering Statistics Course Using Project-based Learning", IEEE Frontiers in Education Conference (FIE),1-4 Oct, 2017.

[3] E. Byl, K. Struyven, G. Van Roosmalen, I. Berghmans, R. Vierendeels, L. Brants, N. Engels, K. Lombaerts, "Peer Assisted Learning implementeren in het hoger onderwijs", Tijdschrift voor Hoger Onderwijs, 32, 205-223, 2011.

[4] European Commission, "Entrepreneurship Education: A guide for Teachers", Brussels, 2014.

[5] S.R. Kirkpatrick, A. Watt, A. Bernal, "Developing an entrepreneurial mindset in engineers: An application of the three C's (creativity, curiosity and connections) in a collaborative summer megacourse", American Society for Engineering Education, 2016. Retrieved from: https://peer.asee.org/ developing-an-entrepreneurial-mindset-in-engineers-an-application-of-the-three-c-s-creativitycuriosity-and-connections-in-a-collaborative-summer-mega-course.pdf

[6] L. S. González, R. F. Castro, M. Á. C. González, J. A. Cendón, "Development of Entrepreneurship Competences from Project Based Learning Approaches", Education in the Knowledge Society (EKS), vol. 17, no. 4, 2016, https://doi.org/10.14201/eks20161741528.

[7] S. Dragoumanos, A. Kakarountas, T. Fourou, "Young technology entrepreneurship enhancement based on an alternative approach of project-based learning", IEEE Global Engineering Education Conference (EDUCON), 25-28 April, 351-358, 2017.

[8] M. Botha, "A project-based learning approach as a method of teaching entrepreneurship to a large group of undergraduate students in South Africa”, Education as Change, 14(2), 213-232, 2010.

[9] L. Hurajova, S. Firsova, M. N. Glukhova, "Project based learning and simulation of setting a company to enhance business mindset of master engineer students and international cooperation skills", 11 $1^{\text {th }}$ International Conference ELEKTRO 2018,1-4 May, 2018. 